\title{
Evaluation of an Intervention to Increase Screening Colonoscopy in an Urban Public Hospital Setting
}

\author{
Denis Nash, Sulaiman Azeez, David Vlahov,
} and Melissa Schori

\begin{abstract}
Only 50\% of New Yorkers aged 50 and over reported ever being screened for colorectal cancer by any modality according to a recent household survey. The objective of this investigation was to assess the impact of a hospital-based intervention aimed at eliminating health care system barriers to timely colorectal cancer screening at Lincoln Medical Center, a large, urban public hospital in one of the nation's poorest census tracts. We conducted a retrospective analysis of all colonoscopies performed over an 11-month period, during which a multi-pronged intervention to increase the number of screening colonoscopies took place. Two "patient navigators" were hired during the study period to provide continuity for colonoscopy patients. A Direct Endoscopic Referral System (DERS) was also implemented. Enhancements to the gastrointestinal (GI) suite were also made to improve operational efficiency. Immediately following the introduction of the patient navigators, there was a dramatic and sustained decline in the broken appointment rates for both screening and diagnostic colonoscopy (from 67\% in May of 2003 to 5\% in June of 2003). The likelihood of keeping the appointment for colonoscopy after the patient navigator intervention increased by nearly 3-fold (relative risk $=2.6,95 \%$ CI 2.2-3.0). The rate of screening colonoscopies increased from 56.8 per month to 119 per month. The screening colonoscopy coverage provided by this facility among persons aged 50 and over in surrounding Zip codes increased from 5.2 to $15.6 \%$ (RR 3.0, 95\% CI 1.94.7). Efforts to increase the number of screening colonoscopies were highly successful, due in large part to the influence of patient navigators, a streamlined referral system, and GI suite enhancements. These findings suggest that there are significant health-care system barriers to colonoscopy that, when addressed, could have a significant impact on screening colonoscopy rates in the general population.
\end{abstract}

KEYWORDS Colorectal cancer, Colonoscopy, Patient navigators, Direct endoscopic referral system, Screening

\section{INTRODUCTION}

Colorectal cancer prevention poses a significant challenge to the public health community. Each year, approximately 140,000 new cases of colorectal cancer are diagnosed in the United States, and approximately 50,000 people die as a result. ${ }^{1}$

\footnotetext{
Nash is with the Center for Urban Epidemiologic Studies, The New York Academy of Medicine, New York, NY, USA, the Department of Epidemiology, International Center for AIDS Care and Treatment Programs, Columbia University, Mailman School of Public Health, New York, NY, USA; Azeez is with the Department of Gastroenterology, Lincoln Medical Center, Bronx, NY, USA; Vlahov is the Director of the Center for Urban Epidemiologic Studies at the New York Academy of Medicine, New York, NY, USA; Schori is with the Office of the Medical Director, Lincoln Medical Center, Bronx, NY, USA.

Correspondence: Denis Nash, Phd, MPH, Columbia University, 722 W. 168th St., Room 706 NY, USA. (E-mail: dn2145@columbia.edu)
} 
The five boroughs of New York City (NYC) have a large number of acute-care hospitals and outpatient endoscopy clinics. ${ }^{2}$ Nonetheless, more than 1,500 New Yorkers die from colorectal cancer each year. ${ }^{3}$ Although screening tests for colorectal cancer are highly effective at detecting cancer early, improving survival, and even preventing the initial development of cancer by removal of precancerous polyps, ${ }^{4}$ colorectal cancer screening uptake is low. National data suggest that only $53 \%$ of U.S. adults age 50 and older are screened for colorectal cancer by fecal occult blood testing (FOBT) or sigmoidoscopy according to recommended schedules. ${ }^{5}$ Recent estimates of colorectal screening by modality suggest that only $33 \%$ of U.S. adults receive FOBT every 2 years, and only $35 \%$ have ever had a sigmoidoscopy. Colorectal cancer screening rates are significantly lower than those for cervical $(83 \%)$ and breast $(70 \%)$ cancer, both of which have improved substantially over the past few decades. ${ }^{5}$ Increasing colorectal cancer screening rates to the same level as cervical and breast cancer screening rates would result in significant reductions in colorectal cancer incidence and mortality.

Increasing colorectal cancer screening rates may be more challenging in some populations than others. Factors that differentiate the likelihood of screening include insurance coverage, source of care, lower income, and age after accounting for sex, racial/ethnic group and educational level, ${ }^{6}$ each of which are also important determinants. Other factors that should influence an individual decision or provider referral for screening include personal risk factors for colorectal cancer such as family history, obesity and exercise, and smoking. ${ }^{7}$ However, even among persons who access the health care system and are referred for colorectal screening, the actual proportion screened can be quite low, suggesting that there are also health care system related barriers to timely colorectal screening, such as a long wait time for appointments. 8,9

In 2003, the New York City Department of Health and Mental Hygiene (NYC DOHMH), together with a coalition of academic medical centers, communitybased organizations and social service agencies in NYC, issued specific guidelines for colorectal cancer screening in NYC. ${ }^{10}$ Most leading national organizations recommend a variety of screening options for colorectal cancer for asymptomatic persons 50 years of age and older. These include a choice of either annual FOBT, flexible sigmoidoscopy every 5 years, or colonoscopy every 10 years. ${ }^{11-13}$ The NYC coalition recommended colonoscopy every 10 years as the preferred colorectal cancer screening test, with annual FOBT as an acceptable, although not optimal, alternative for those unwilling or unable to undergo colonoscopy. The rationale for the focused recommendation was based on the reported higher sensitivity of colonoscopy compared with FOBT and sigmoidoscopy ${ }^{11}$ and on NYC's high number of gastroenterologists per capita.

This report provides an assessment of a multi-faceted intervention implemented in 2003 to increase the number of screening colonoscopies performed at Lincoln Medical Center in the Highbridge and Morrisania section of the Bronx.

\section{MATERIALS AND METHODS}

\section{Setting}

Lincoln Medical Center is situated in the Highbridge/Morrisania section of the Bronx and is one of 11 acute care public hospitals in NYC that comprise the New York City Health and Hospital Corporation (HHC). The Lincoln Medical Center 
patient population is drawn from the nation's poorest census tract and is predominantly Latino (57\%) and black (38\%), with approximately $30 \%$ being foreign born. Lincoln Medical Center houses one of the busiest emergency rooms in the nation, with over 150,000 visits per year.

\section{Intervention to Increase Screening Colonoscopy at Lincoln}

Prior to August of 2003, patients were referred for screening colonoscopy through either the GI or colorectal clinic where they would first receive medical clearance for the procedure. The clinic patients were referred to either the GI or colorectal clinic for evaluation by a medical gastroenterologist or surgical endoscopist, depending on which clinic had the shorter wait time for appointments. The typical minimum wait time for appointments was $8-10$ weeks in the GI clinic and 3 months in the colorectal clinic, plus an additional 2-4 weeks for medical and financial clearance through pre-admission testing (PAT). In addition to the long wait time at the GI and colorectal clinics, patients were expected to navigate through a fairly complex medical system.

Patient Navigators Beginning in May 2003, two "patient navigators" were hired to assist patients in obtaining a colonoscopy (both screening and diagnostic). The purpose of the patient navigators was to increase efficiency and provide continuity for the patients at various points from the time of referral to the completion of the colonoscopy procedure (Fig. 1). Specifically, patient navigators assisted patients in completing paperwork for PAT, scheduling appointments, and providing appointment reminders immediately prior to the scheduled appointments. The patient navigators were available to facilitate referrals either through the GI or colorectal clinic. The patient navigators were expected to improve the uptake of screening colonoscopy by reducing the broken appointment rate, which was more than $50 \%$ prior to May of 2003.

Direct Endoscopic Referral System (DERS) To reduce the wait time between referral for screening colonoscopy and receiving an appointment for the procedure,

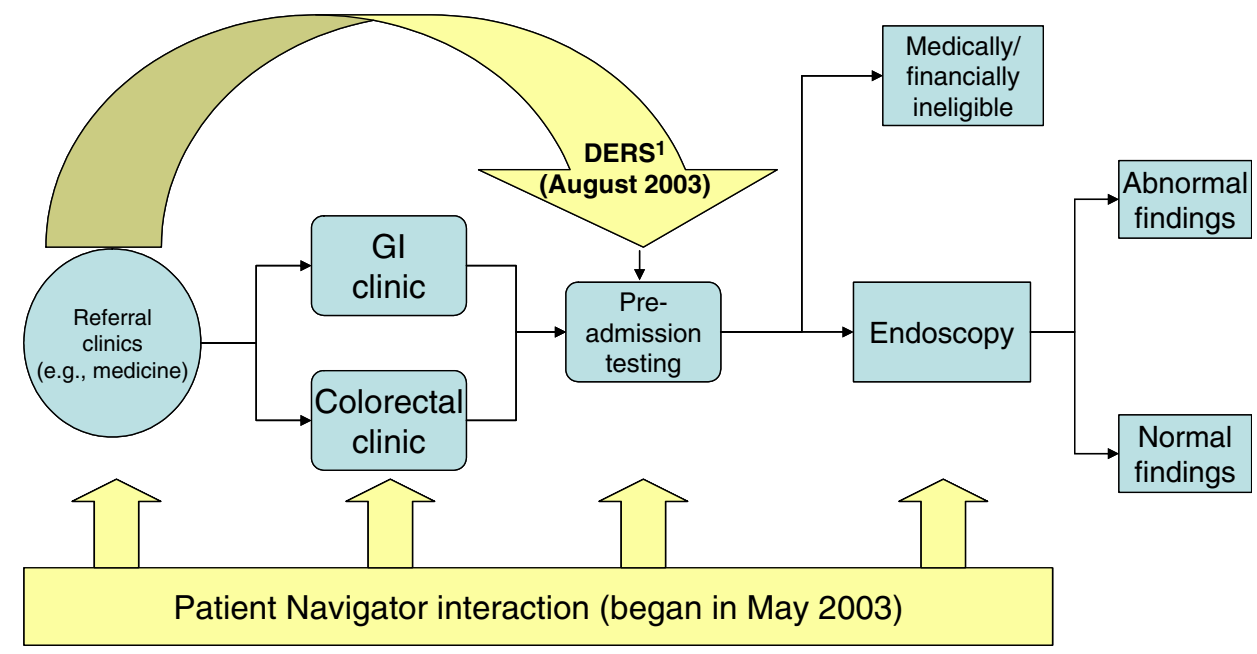

${ }^{1}$ DERS=Direct Endoscopic Referral System

FIGURE 1. Schematic of colonoscopy referrals at Lincoln Hospital. 
Lincoln Medical Center introduced the Direct Endoscopic Referral System (DERS) in August of 2003, which allows the primary care physician to use standard guidelines for screening and diagnostic colonoscopies and to refer patients directly to PAT for the necessary clearance and scheduling for the colonoscopy appointment (Fig. 1). The DERS program bypasses medical clearance appointments at either the GI or colorectal clinics, reducing the wait time between scheduling and receipt of colonoscopy.

GI Suite Enhancements In September of 2003, several enhancements were made to the GI suite to improve operational efficiency. These included the addition of more equipment such as colonoscopes and video processors; colonoscope cleaning was moved from the basement to the GI suite, resulting in faster turnaround time and less potential for damage to the colonoscopes; the GI suite recovery areas were redesigned such that one registered nurse (RN) could now monitor at least four patients (allowing more nurses to be assigned to the procedure rooms); finally, an anesthesiologist performed the required moderate sedation and completed all paperwork (reducing the procedure time by an estimated 10 to 15 min per case).

\section{Evaluation Methods}

Data presented here are based on all colonoscopies performed at Lincoln Medical Center $(N=1,767,707$ diagnostic and 1,060 screening) during the 11-month time period April 2003-February 2004, which bracketed the implementation of the Patient Navigator/DERS intervention. Patients referred from the General Medicine Clinic had information on the broken appointment rates.

\section{Analysis and Definitions}

In order to compare the volume of screening colonoscopies before and after the Patient Navigator/DERS intervention, the number of colonoscopies and the average colonoscopy rate per month were tabulated by demographic characteristics and indication for colonoscopy. The pre and post time period cutoff point was set at August 2003 to allow for an analysis of the combined impact of the patient navigators (implemented in May 2003) and DERS (implemented in August 2003). Choosing an earlier cutoff (e.g., May 2003) would have resulted in a small sample size for the baseline period (i.e., March and April 2003 only). Because the number of months with available data pre and post intervention are different (4 and 7 months, respectively), the average monthly rate of colonoscopies was analyzed to facilitate comparison of the pre and post intervention period. During the course of the study, data collection procedures were modified to allow recording of an "other" category of race/ethnicity, in addition to non-Hispanic black, Hispanic, and non-Hispanic white, making it necessary to interpret race/ethnicity associations with caution.

The broken appointment rate was defined as the proportion of patients who were medically and financially cleared through the PAT process and who were scheduled for colonoscopy but who did not show up for their colonoscopy appointment. The broken appointment rate was calculated for each month in 2003 among those patients referred from the general medicine clinic $(n=898)$. 
Estimating the Coverage of Screening Colonoscopy in Surrounding Zip Codes To estimate the amount of screening colonoscopy coverage provided by Lincoln Medical Center to the surrounding community, the number of screening colonoscopies per month among persons from Zip codes adjacent to Lincoln Medical Center (i.e., 10451, 10452, 10454, 10455, and 10456) was divided by the number of persons over age 50 who would be expected to receive a screening colonoscopy if the entire population of persons aged 50 and over in these Zip codes were screened

TABLE 1. Characteristics of persons receiving diagnostic and screening colonoscopy, Lincoln Hospital, 2003-2004

\begin{tabular}{|c|c|c|c|c|c|c|}
\hline & \multicolumn{3}{|c|}{ April-July 2003} & \multicolumn{3}{|c|}{ August 2003-Feb 2004} \\
\hline & $N$ & Percent & $\begin{array}{l}\text { Average } \\
\text { number } \\
\text { per month }\end{array}$ & $N$ & Percent & $\begin{array}{l}\text { Average } \\
\text { number } \\
\text { per month }\end{array}$ \\
\hline Total & 470 & 100 & 117.5 & 1297 & 100 & 185.3 \\
\hline \multicolumn{7}{|l|}{ Sex } \\
\hline $\mathrm{F}$ & 278 & 59 & 69.5 & 795 & 61 & 113.6 \\
\hline M & 192 & 41 & 48.0 & 502 & 39 & 71.7 \\
\hline Unknown & & & & 4 & 0 & 0.6 \\
\hline \multicolumn{7}{|l|}{ Race } \\
\hline Non-Hispanic black & 78 & 17 & 19.5 & 78 & 6 & 11.1 \\
\hline Hispanic & 369 & 79 & 92.3 & 902 & 69 & 128.9 \\
\hline Other/unknown & 23 & 5 & 5.8 & 321 & 25 & 45.9 \\
\hline \multicolumn{7}{|l|}{ Age } \\
\hline $0-40$ & 25 & 5 & 6.3 & 48 & 4 & 6.9 \\
\hline $40-44$ & 21 & 4 & 5.3 & 45 & 3 & 6.4 \\
\hline $45-49$ & 29 & 6 & 7.3 & 59 & 5 & 8.4 \\
\hline $50-54$ & 77 & 16 & 19.3 & 225 & 17 & 32.1 \\
\hline $55-59$ & 79 & 17 & 19.8 & 270 & 21 & 38.6 \\
\hline $60-64$ & 72 & 15 & 18.0 & 260 & 20 & 37.1 \\
\hline $65-69$ & 73 & 16 & 18.3 & 197 & 15 & 28.1 \\
\hline $70-74$ & 51 & 11 & 12.8 & 115 & 9 & 16.4 \\
\hline $75+$ & 43 & 9 & 10.8 & 80 & 6 & 11.4 \\
\hline Unknown & & & & 2 & 0 & 0.3 \\
\hline \multicolumn{7}{|l|}{ Insurance } \\
\hline Medicaid & 149 & 32 & 37.3 & 495 & 38 & 70.7 \\
\hline Medicaid/medicare & 115 & 24 & 28.8 & 263 & 20 & 37.6 \\
\hline Medicare & 80 & 17 & 20.0 & 87 & 7 & 12.4 \\
\hline Uninsured & 49 & 10 & 12.3 & 218 & 17 & 31.1 \\
\hline MetroPlus & 48 & 10 & 12.0 & 118 & 9 & 16.9 \\
\hline Other & 29 & 6 & 7.3 & 116 & 8 & 16.6 \\
\hline \multicolumn{7}{|c|}{ Indication for colonoscopy } \\
\hline Screening & 227 & 48 & 56.8 & 833 & 64 & 119.0 \\
\hline Anemia & 46 & 10 & 11.5 & 118 & 9 & 16.9 \\
\hline Rectal bleeding & 36 & 8 & 9.0 & 111 & 9 & 15.9 \\
\hline$+\mathrm{FOBT}$ & 34 & 7 & 8.5 & 36 & 3 & 5.1 \\
\hline GI bleeding & 33 & 7 & 8.3 & 38 & 3 & 5.4 \\
\hline Other & 94 & 21 & 23.5 & 165 & 11 & 23.6 \\
\hline \multicolumn{7}{|l|}{ Navigator } \\
\hline No & 419 & 89 & 104.8 & 755 & 58 & 107.9 \\
\hline Yes & 51 & 11 & 12.8 & 546 & 42 & 78.0 \\
\hline
\end{tabular}


every 10 years. For example, there are 9,887 persons aged 50 and over in Zip code 10451, each of whom would be targeted for screening by colonoscopy every 10 years. If the screening of this target population is distributed equally over 10 year's time with $100 \%$ coverage, we would expect that 989 persons would be screened each year (i.e., 9,887 persons divided by 10), or approximately 83 persons per month (i.e., 989 persons divided by 12 months). The actual number of monthly screening colonoscopies performed at Lincoln Medical Center was compared with the target number of screening colonoscopies for Zip code 10451 (Zip code of Lincoln Medical Center) as well as all adjacent Zip codes to estimate the proportion of the colonoscopy screening target in the community covered by Lincoln Medical Center both before and after the Patient Navigator/DERS intervention.

\section{RESULTS}

\section{All Colonoscopies}

Table 1 shows the number and characteristics of persons receiving colonoscopy (screening or diagnostic) at Lincoln Medical Center over an 11-month period before and after the Patient Navigator/DERS intervention. The proportion of males receiving colonoscopies did not change appreciably $p_{\chi^{2}}=0.4143$. The proportion of uninsured persons who received colonoscopy increased from 10 to $17 \%$ before and after the intervention, respectively, $p_{\chi^{2}}<0.001$. The proportion of colonoscopies that had a patient navigator associated with them increased from 11 to $42 \%$ $p_{\chi^{2}}<0.001$. While both screening and diagnostic colonoscopies increased as the

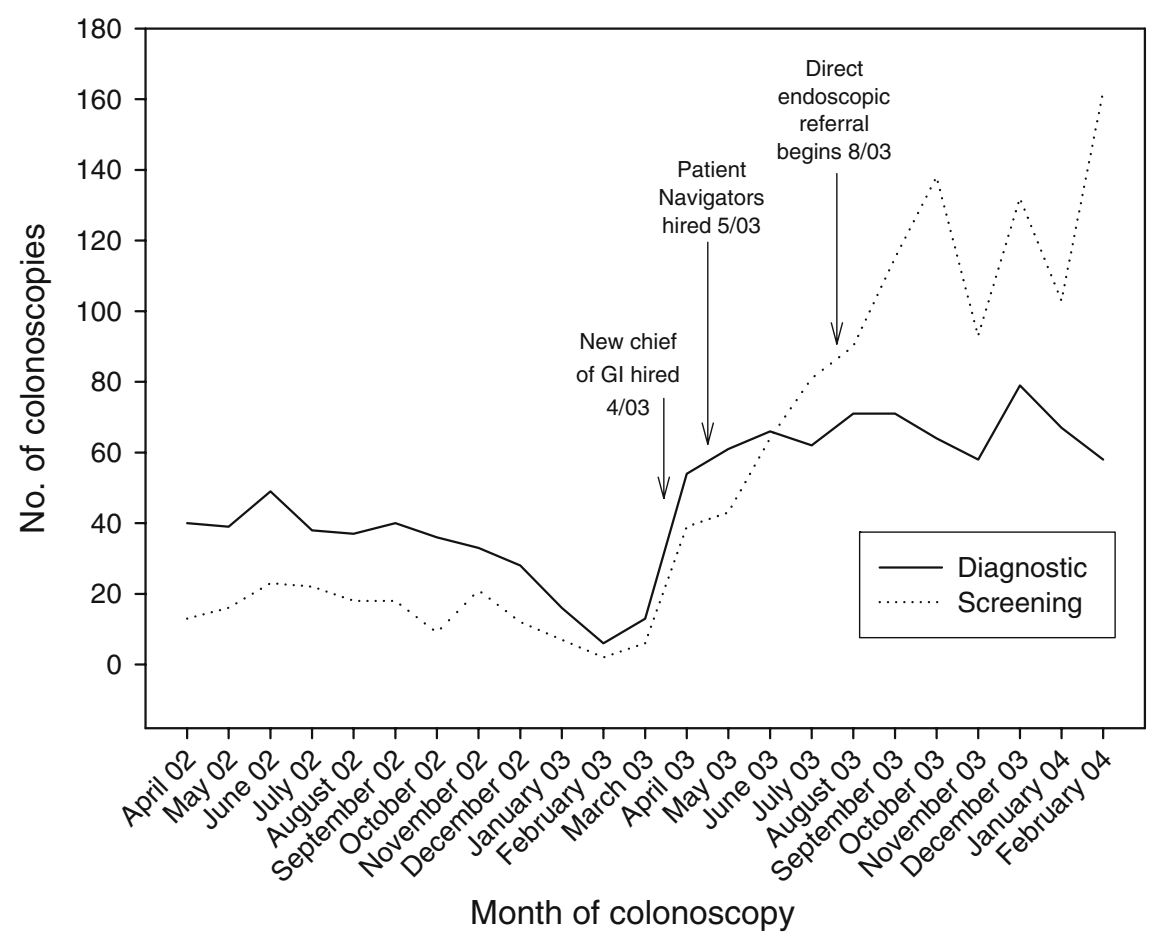

FIGURE 2. Number of diagnostic and screening colonoscopies by month and indication for colonoscopy, Lincoln Hospital, 2002-2004. 
intervention was phased in, the number of screening colonoscopies increased more with time (Fig. 2). Persons receiving screening colonoscopy at Lincoln Hospital during March 2003-February 2004 came from 48 Zip codes in four NYC boroughs, with the majority coming from nearby Zip codes in the Bronx.

\section{Screening Colonoscopies}

Among those persons receiving screening colonoscopies $(n=1,060$, Table 2$)$, the average number of persons screened per month increased from 75.7 to 119.0 before and after the intervention, respectively. There was no difference in the proportion of males screened by colonoscopy between the two periods. The age distribution of those screened after the intervention began appeared to be slightly younger than that prior. The proportion of persons screened who were on Medicaid was higher

TABLE 2. Characteristics of persons receiving screening colonoscopy, Lincoln Hospital, 2003-2004

\begin{tabular}{|c|c|c|c|c|c|c|}
\hline & \multicolumn{3}{|c|}{ April-July 2003} & \multicolumn{3}{|c|}{ August 2003-Feb 2004} \\
\hline & $N$ & Percent & $\begin{array}{l}\text { Average } \\
\text { number } \\
\text { per month }\end{array}$ & $N$ & Percent & $\begin{array}{l}\text { Average } \\
\text { number } \\
\text { per month }\end{array}$ \\
\hline Total & 227 & 100 & 56.8 & 833 & 100 & 119.0 \\
\hline \multicolumn{7}{|l|}{ Sex } \\
\hline $\mathrm{F}$ & 150 & 66 & 37.5 & 532 & 64 & 76.0 \\
\hline M & 77 & 34 & 19.3 & 299 & 36 & 42.7 \\
\hline Unknown & 0 & 0 & 0.0 & 2 & 0 & 0.3 \\
\hline \multicolumn{7}{|l|}{ Race } \\
\hline Non-Hispanic black & 26 & 11 & 6.5 & 42 & 5 & 6.0 \\
\hline Hispanic & 187 & 82 & 46.8 & 616 & 74 & 88.0 \\
\hline Other/unknown & 14 & 6 & 3.5 & 175 & 21 & 25.0 \\
\hline \multicolumn{7}{|l|}{ Age } \\
\hline $0-40$ & 1 & 0 & 0.3 & 2 & 0 & 0.3 \\
\hline $40-44$ & 2 & 1 & 0.5 & 5 & 1 & 0.7 \\
\hline $45-49$ & 4 & 2 & 1.0 & 17 & 2 & 2.4 \\
\hline $50-54$ & 43 & 19 & 10.8 & 159 & 19 & 22.7 \\
\hline $55-59$ & 48 & 21 & 12.0 & 198 & 24 & 28.3 \\
\hline $60-64$ & 42 & 19 & 10.5 & 201 & 24 & 28.7 \\
\hline $65-69$ & 47 & 21 & 11.8 & 137 & 16 & 19.6 \\
\hline $70-74$ & 23 & 10 & 5.8 & 81 & 10 & 11.6 \\
\hline $75+$ & 17 & 7 & 4.3 & 32 & 4 & 4.6 \\
\hline Unknown & 0 & 0 & 0.0 & 1 & 0 & 0.1 \\
\hline \multicolumn{7}{|l|}{ Insurance } \\
\hline Medicaid & 68 & 30 & 17.0 & 339 & 41 & 48.4 \\
\hline Medicaid/medicare & 48 & 21 & 12.0 & 170 & 20 & 24.3 \\
\hline Medicare & 36 & 16 & 9.0 & 50 & 6 & 7.1 \\
\hline Uninsured & 31 & 14 & 7.8 & 124 & 15 & 17.7 \\
\hline MetroPlus & 31 & 14 & 7.8 & 84 & 10 & 12.0 \\
\hline Other & 13 & 6 & 3.3 & 66 & 7 & 9.4 \\
\hline \multicolumn{7}{|l|}{ Navigator } \\
\hline No & 204 & 90 & 51.0 & 458 & 55 & 65.4 \\
\hline Yes & 23 & 10 & 5.8 & 375 & 45 & 53.6 \\
\hline
\end{tabular}


TABLE 3. Findings among persons receiving screening colonoscopy, Lincoln Hospital, 20032004

\begin{tabular}{lrrrrr}
\hline & \multicolumn{2}{c}{ April-July 2003 } & & \multicolumn{2}{c}{ August 2003-Feb 2004 } \\
\cline { 2 - 3 } & $N$ & Percent & & $N$ & Percent \\
\cline { 2 - 3 } Total & 227 & 100 & & 833 & 100 \\
No polyps & 181 & 80 & 622 & 75 \\
Adenoma/tubular adenoma & 25 & 11 & 119 & 14 \\
Other & 10 & 4 & 49 & 6 \\
Hyperplasia & 11 & 5 & 35 & 4 \\
Cancer & 0 & 0 & 8 & 1 \\
\hline
\end{tabular}

after the intervention $p_{\chi^{2}}<0.001$. A patient navigator was associated with $45 \%$ of all screening colonoscopies during the 7-month period following the intervention (Table 2). Table 3 shows the distribution of screening colonoscopy findings by time period. Eight cancers were detected in the post intervention period compared with zero in pre-intervention period.

\section{Broken Appointment Rates for Colonoscopy Suite}

Using data on those patients cleared for colonoscopy by pre-admission testing, the broken colonoscopy appointment rate declined from 67.2\% in May 2003 to $5.3 \%$ in June 2003 and was sustained (Fig. 3). The likelihood of keeping the appointment for colonoscopy after the patient navigators were hired compared with before increased by nearly three-fold (relative risk $=2.6,95 \%$ CI $2.2-3.0$ ).

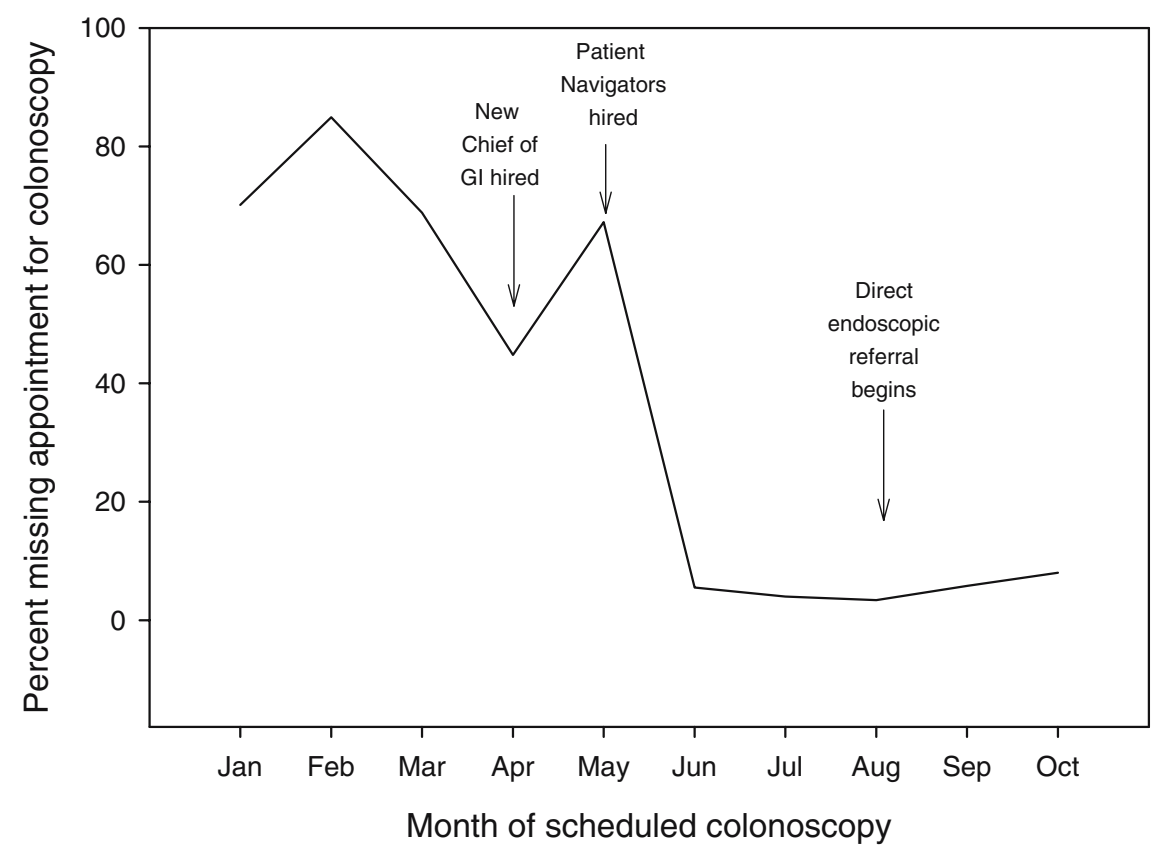

FIGURE 3. Broken appointment rate for colonoscopy versus time among patients completing preadmission testing at Lincoln Hospital, Jan-Oct, 2003. 


\section{Screening Colonoscopy Coverage in Adjacent Zip Codes}

Table 4 shows the number of residents in Zip code 10451 and each of the adjacent Zip codes by sex, race/ethnicity, and age group. Of the 262,196 persons in all the Zip codes combined, there are 50,056 persons who are aged 50 years or over and were considered eligible for screening by colonoscopy every 10 years. If the target is to screen $100 \%$ of these residents every 10 years, then approximately 5,006 residents should be screened each year, or about 417 per month. Because of differences in the population sizes and age distribution by Zip code, the estimated monthly target varies by Zip code from 59 to 120 per month.

To compare how much colorectal screening coverage was being provided by Lincoln Hospital in the surrounding area of the hospital before and after the Patient Navigator/DERS/Efficiency intervention, the number of persons screened per month at Lincoln was divided by the monthly target for each Zip code (Table 5). Overall, $7 \%$ of the target number of persons in the area surrounding Lincoln Medical Center received screening colonoscopy each month prior to the intervention. The coverage more than doubled to $15.6 \%$ after the intervention was fully implemented. An increase in the proportion of the monthly target screened was observed in all adjacent Zip codes and nearly all demographic subgroups and age groups (Fig. 4).

\section{DISCUSSION}

Efforts to increase the number of screening colonoscopies performed and enhancements to improve operational efficiency of the GI Suite at Lincoln Medical Center appear to have been highly successful, due in large part to the influence of patient navigators and a streamlined referral system. It's difficult to tease out the individual

TABLE 4. Number of residents eligible for screening colonoscopy in 2000 , and the annual and monthly targets for colonoscopy screening if $\mathbf{1 0 0 \%}$ of residents aged $\mathbf{5 0}$ and over are screened every $\mathbf{1 0}$ years in Zip codes including and adjacent to Lincoln Hospital

\begin{tabular}{lrcr}
\hline & \multicolumn{3}{c}{ All adjacent Zip codes } \\
\cline { 2 - 4 } & & \multicolumn{2}{c}{ Number to screen } \\
\cline { 2 - 4 } & $N$ & Annually & Monthly \\
\hline Total population & 262,196 & $\mathrm{n} / \mathrm{a}$ & $\mathrm{n} / \mathrm{a}$ \\
Population 50+ & 50,056 & 5,006 & 417 \\
Sex (among population 50+) & & & \\
$\quad$ Female & 30,002 & 3,000 & 250 \\
Male & 20,054 & 2,005 & 167 \\
Race/ethnicity (among population 50+) & & & \\
Black & 19,365 & 1,937 & 161 \\
Hispanic & 28,100 & 2,810 & 234 \\
White/other & 1,624 & 162 & 14 \\
Age & & & 106 \\
50-54 & 12,662 & 1,266 & 85 \\
55-59 & 10,244 & 1,024 & 71 \\
$60-64$ & 8,564 & 856 & 53 \\
65-69 & 6,414 & 641 & 40 \\
$70-74$ & 4,781 & 478 & 62 \\
$75+$ & 7,391 & 739 & \\
\hline
\end{tabular}


TABLE 5. Estimate coverage for screening colonoscopy provided by Lincoln Hospital before and after a direct referral and patient navigator intervention

\begin{tabular}{|c|c|c|c|c|c|c|c|c|c|c|}
\hline & \multicolumn{5}{|c|}{ April-July 2003} & \multicolumn{5}{|c|}{ August 2003-Feb 2004} \\
\hline & $N$ & Percent & $\begin{array}{l}\text { Average } \\
\text { number } \\
\text { per } \\
\text { month }\end{array}$ & $\begin{array}{l}\text { Monthly } \\
\text { target }\end{array}$ & $\begin{array}{l}\text { Coverage } \\
\text { by Lincoln } \\
(\%)\end{array}$ & $N$ & Percent & $\begin{array}{l}\text { Average } \\
\text { number } \\
\text { per } \\
\text { month }\end{array}$ & $\begin{array}{l}\text { Monthly } \\
\text { target }\end{array}$ & $\begin{array}{c}\text { Coverage } \\
\text { by Lincoln } \\
(\%)\end{array}$ \\
\hline Total & 87 & 100 & 21.8 & 417 & 5.2 & 456 & 100 & 65.1 & 417 & 15.6 \\
\hline \multicolumn{11}{|l|}{ Sex } \\
\hline $\mathrm{F}$ & 57 & 66 & 14.3 & 250 & 5.7 & 295 & 65 & 42.1 & 250 & 16.9 \\
\hline$M$ & 30 & 34 & 7.5 & 167 & 4.5 & 161 & 35 & 23.0 & 167 & 13.8 \\
\hline \multicolumn{11}{|l|}{ Race } \\
\hline $\begin{array}{l}\text { Non-Hispanic } \\
\text { black }\end{array}$ & 11 & 13 & 2.8 & 161 & 1.7 & 27 & 6 & 3.9 & 161 & 2.4 \\
\hline Hispanic & 70 & 80 & 17.5 & 234 & 7.5 & 330 & 72 & 47.1 & 234 & 20.1 \\
\hline $\begin{array}{l}\text { Other/ } \\
\text { unknown }\end{array}$ & 6 & 7 & 1.5 & 14 & 11.1 & 99 & 22 & 14.1 & 14 & 104.5 \\
\hline \multicolumn{11}{|l|}{ Age } \\
\hline $0-40$ & 1 & 1 & 0.3 & & & 1 & 0 & 0.1 & & \\
\hline $40-44$ & 1 & 1 & 0.3 & & & 3 & 1 & 0.4 & & \\
\hline $45-49$ & 1 & 1 & 0.3 & & & 9 & 2 & 1.3 & & \\
\hline $50-54$ & 13 & 15 & 3.3 & 106 & 3.1 & 80 & 18 & 11.4 & 106 & 10.8 \\
\hline $55-59$ & 14 & 16 & 3.5 & 85 & 4.1 & 112 & 25 & 16.0 & 85 & 18.7 \\
\hline $60-64$ & 19 & 22 & 4.8 & 71 & 6.7 & 103 & 23 & 14.7 & 71 & 20.6 \\
\hline $65-69$ & 21 & 24 & 5.3 & 53 & 9.8 & 78 & 17 & 11.1 & 53 & 20.8 \\
\hline $70-74$ & 10 & 11 & 2.5 & 40 & 6.3 & 48 & 11 & 6.9 & 40 & 17.2 \\
\hline $75+$ & 7 & 8 & 1.8 & 62 & 2.8 & 22 & 5 & 3.1 & 62 & 5.1 \\
\hline
\end{tabular}

contributions of each, as well as other contributing factors, but it seems reasonable to conclude that all, in one way or another, made an impact. By comparing the difference in the monthly coverage rates before and after the implementation of the combined Patient Navigator/DERS intervention, it was possible to evaluate the impact of the entire intervention. The broken appointment rate declined immediately after the patient navigators started at Lincoln Hospital and before the implementation of the DERS. It was therefore possible to attribute the reduction in the broken appointment rate and the associated increase in screening colonoscopy to the patient navigation component of the intervention. Though it was not possible to discern the relative contribution of each component of the intervention but only their combined impact, it is clear that both of these factors increased the number of screening colonoscopies delivered at Lincoln Hospital.

Other contributing factors to the success of the intervention appear to include the hiring of a new Chief of GI who has a commitment to increasing screening colonoscopies and a willingness to try the direct endoscopic referral system (DERS). Additionally, the surgical endoscopists at Lincoln Medical Center agreed to expand their coverage to include screening colonoscopy. Finally, the GI suite was expanded and enhanced to streamline colonoscopy procedures. Since most of these enhancements anteceded the increase in colonoscopies and reduction in the broken appointment rates, it is difficult to assess their impact. However, they may have contributed to the sustainability of the intervention. 


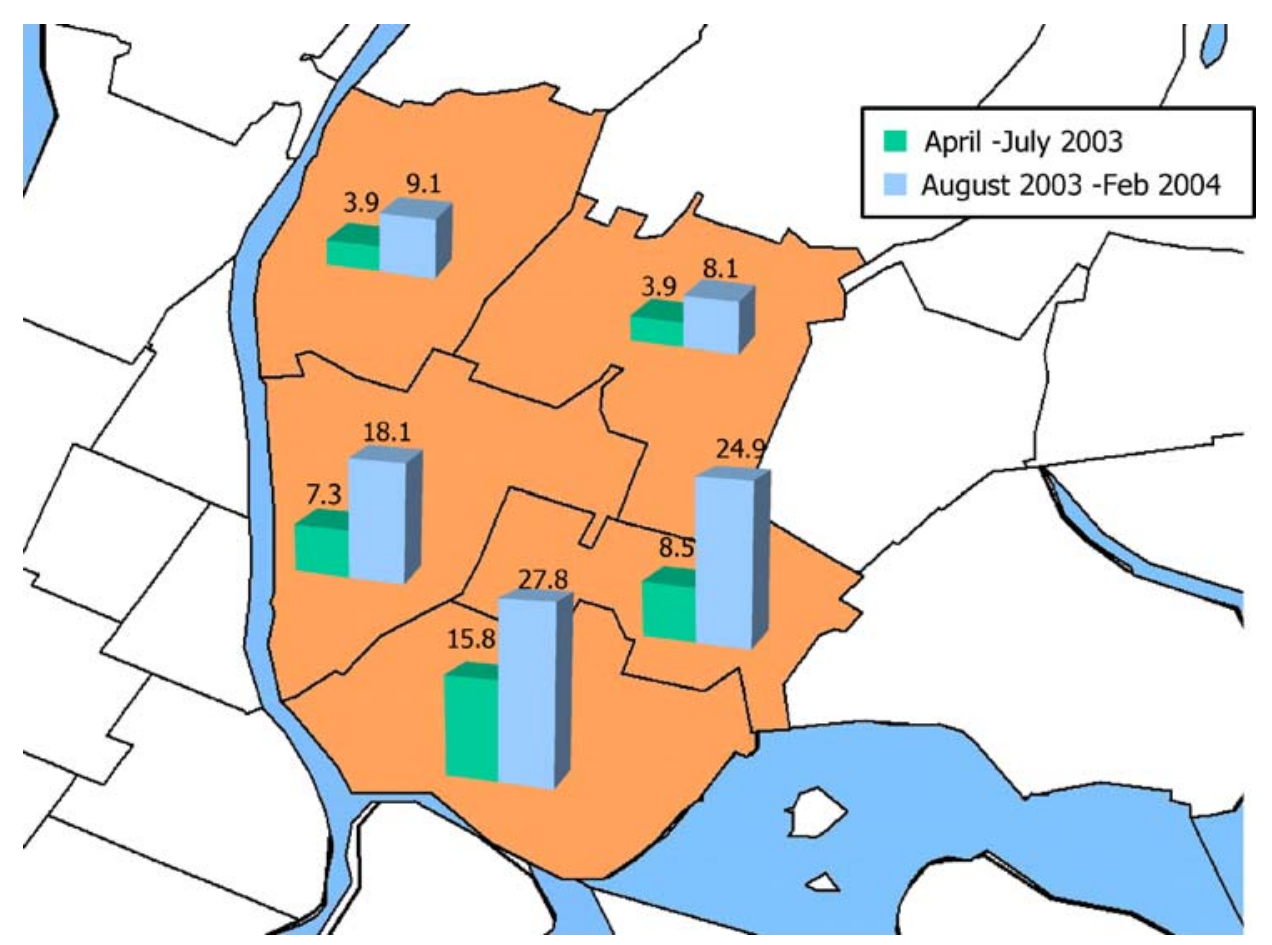

FIGURE 4. Estimated coverage of screening colonoscopy provided by Lincoln Hospital in surrounding zip codes before and after a Patient Navigator/DERS intervention.

Cancer ranks second in the causes of death among residents of Highbridge and Morrisania, and the death rate due to all cancers is $50 \%$ higher there compared with the rest of NYC. ${ }^{14}$ In a recent telephone survey conducted by the New York City Department of Health and Mental Hygiene, only 44\% of adults aged 50 or over in Highbridge and Morrisania reported ever being screened for colorectal cancer by any modality (colonoscopy, sigmoidoscopy, or FOBT) ${ }^{14}$ the citywide average was $50 \%$. Also, $41.7 \%$ of persons reported having received a colonoscopy in the preceding 10 years, $9.5 \%$ had a sigmoidoscopy in the last 5 years, and $31.9 \%$ reported an FOBT in the preceding 2 years. ${ }^{8,15}$ The efforts at Lincoln Medical Center appear to have resulted in a sustained increase in the coverage of colonoscopy in the surrounding neighborhoods.

There are several limitations of this analysis worth noting. First, the evaluation utilized a before and after comparison. Since there was no concurrent internal comparison group, we cannot rule out the possibility that some other factor that changed during the course of the intervention is responsible for the observed increase. Additionally, due to limited staff and resources, we had very little data on patients who received colonoscopies and almost no data on those referred who didn't receive colonoscopies. Ideally we would have had interviewed all or a sample of patients in each group to assess perceived barriers and enabling factors for the receipt of screening colonoscopy. We could not assess the degree to which patients who missed appointments were subsequently rescheduled and received colonoscopy. As such, we may have overestimated the broken appointment rate in our study. Finally, because of changes in the way that race/ethnicity data were collected 
during the study period, we could not reliably assess changes in colonoscopy rates and coverage by race/ethnicity.

The results of our investigation suggest that there are health care system barriers to patients receiving screening colonoscopy that, when addressed, can result in substantial improvements in the coverage of screening colonoscopy in the surrounding communities. Other types of barriers outside the health care system exist at the individual (e.g., knowledge of the need for screening and employment status) and community levels (e.g., lack of a nearby medical facility or access to public transportation) and should also be addressed. Individual-level barriers to receiving colorectal cancer screening and colonoscopy appear to include age, race/ ethnicity, income, and insurance. ${ }^{9,15}$ Education and a lack of awareness of the need to be screened has been shown to be associated with the likelihood of screening for colorectal and other cancers. ${ }^{6,16}$

Characteristics of the physical and social environment in neighborhoods, peer and social networks, public policies and interventions, and access to quality health care may also affect the likelihood of practicing preventive behaviors such as cancer screening and the subsequent risk of disease. ${ }^{17-19}$ For example, "neighborhood social environment" has been associated with hypertension, ${ }^{20}$ low birth weight ${ }^{21}$ and high-risk sexual behaviors among women. ${ }^{22}$ As Diez Roux has argued, “[n]eighborhood differences are not 'naturally' determined but rather result from social and economic processes influenced by specific policies. As such, they are eminently modifiable and susceptible to intervention." 18 The role of such factors as barriers to receiving timely colorectal cancer screening has not been systematically studied and may yield important information for future interventions to improve colorectal cancer screening rates.

\section{CONCLUSION}

In an urban public hospital setting, a multi-faceted intervention led to marked increases in screening colonoscopy rates and thereby improved potential for earlier detection of malignant and pre-malignant disease in the surrounding community, which ultimately should lead to a decrease in colorectal cancer deaths. Future research and interventions should seek to assess and address individual and neighborhood level barriers to timely colorectal cancer screening.

\section{ACKNOWLEDGEMENT}

This work was supported in part by a grant from the Fund for the City of New York and with funds from the City Council of New York.

\section{REFERENCES}

1. Cancer Facts and Figures. Atlanta: American Cancer Society; 2003.

2. CNN Money, Best Places to Live, New York, New York. money.cnn.com/best/bplive/ details/3651000.html. Accessed March 21, 2004.

3. Summary of Vital Statistics 2002. New York: New York City Department of Health and Mental Hygiene; 2003.

4. Pignone M, Rich M, Teutsch SM, Berg AO, Lohr KN. Screening for colorectal cancer in adults at average risk: a summary of the evidence for the U.S. Preventive Services Task Force. Ann Intern Med. Jul 16 2002;137(2):132-141. 
5. Weir HK, Thun MJ, Hankey BF, et al. Annual report to the nation on the status of cancer, 1975-2000, featuring the uses of surveillance data for cancer prevention and control. J Natl Cancer Inst. Sep 3 2003;95(17):1276-1299.

6. Breen N, Wagener DK, Brown ML, Davis WW, Ballard-Barbash R. Progress in cancer screening over a decade: results of cancer screening from the 1987, 1992, and 1998 National Health Interview Surveys. J Natl Cancer Inst. Nov 21 2001;93(22):1704-1713.

7. Giovannucci E. Modifiable risk factors for colon cancer. Gastroenterol Clin North Am. Dec 2002;31(4):925-943.

8. Thorpe LE, Mostashari F, Hajat A, et al. Colon cancer screening practices in New York City, 2003: results of a large random-digit dialed telephone survey. Cancer. Sep 1 2005;104(5):1075-1082.

9. Vlahov D, Ahern J, Vazquez T, et al. Racial/ethnic differences in screening for colon cancer: report from the New York Cancer Project. Ethn Dis. 2005 Winter;15(1):76-83.

10. Feldman G, McCord C, Frieden TR. City Health Information: Preventing colorectal cancer. New York: New York City Department of Health and Mental Hygiene; 2003.

11. Winawer S, Fletcher R, Rex D, et al. Colorectal cancer screening and surveillance: clinical guidelines and rationale-update based on new evidence. Gastroenterology. Feb 2003;124(2):544-560.

12. Byers T, Levin B, Rothenberger D, Dodd GD, Smith RA. American Cancer Society guidelines for screening and surveillance for early detection of colorectal polyps and cancer: update 1997. American Cancer Society Detection and Treatment Advisory Group on Colorectal Cancer. CA Cancer J Clin. May-Jun 1997;47(3):154-160.

13. Berg AO. Screening for colorectal cancer: recommendations and rationale. Am J Nurs. Sep 2002;102(9):107-117.

14. Karpati AM, Lu X, Mostashari F, Thorpe L, Frieden TR. Community Health Profiles: The Health of Highbridge and Morrisania, Bronx. New York: New York City Department of Health and Mental Hygiene; 2003.

15. Thorpe L, Mostashari F, Feldman G, et al. Cancer Screening in New York City: We can do much better. New York City Department of Health and Mental Hygiene; 2003.

16. Finney Rutten LJ, Nelson DE, Meissner HI. Examination of population-wide trends in barriers to cancer screening from a diffusion of innovation perspective (1987-2000). Prev Med Mar. 2004;38(3):258-268.

17. Healthy People 2010: Understanding and Improving Health 2000. Washington, District of Columbia: US Department of Health and Human Services; 2002.

18. Diez Roux AV, Merkin SS, Arnett D, et al. Neighborhood of residence and incidence of coronary heart disease. N Engl J Med. Jul 12 2001;345(2):99-106.

19. Yen IH, Syme SL. The social environment and health: a discussion of the epidemiologic literature. Annu Rev Public Health. 1999;20:287-308.

20. Diez Roux AV. Invited commentary: places, people, and health. Am J Epidemiol. Mar 15 2002;155(6):516-519.

21. O'Campo P, Xue X, Wang MC, Caughy M. Neighborhood risk factors for low birthweight in Baltimore: a multilevel analysis. Am J Public Health. Jul 1997; 87(7):1113-1118.

22. Singh S, Darroch JE, Frost JJ. Socioeconomic disadvantage and adolescent women's sexual and reproductive behavior: the case of five developed countries. Fam Plann Perspect. Nov-Dec 2001;33(6):251-258, 289. 